\title{
Methods to Analyze Flexural Buckling of the Consequent Slabbed Rock Slope under Top Loading
}

\author{
Hongyan Liu, Guihe Wang, and Feng Huang \\ College of Engineering \& Technology, China University of Geosciences, Beijing, Beijing 100083, China \\ Correspondence should be addressed to Hongyan Liu; lhyan1204@126.com
}

Received 6 May 2016; Accepted 26 June 2016

Academic Editor: Paolo Maria Mariano

Copyright (C) 2016 Hongyan Liu et al. This is an open access article distributed under the Creative Commons Attribution License, which permits unrestricted use, distribution, and reproduction in any medium, provided the original work is properly cited.

\begin{abstract}
The consequent slabbed rock slope is prone to flexural buckling failure under its self-weight and top loading. However, nearly none of the existing studies consider the effect of the top loading on the slope flexural critical buckling height $(\mathrm{CBH})$. Therefore, on the basis of Euler's Method and the flexural buckling failure mode of the consequent slabbed rock slope, the calculation method of the $\mathrm{CBH}$ of the vertical slabbed rock slope under the self-weight is firstly proposed, and then it is extended to that of the consequent slabbed rock slope. The effect of slope dip angle, friction angle, and cohesion between the neighboring rock slabs and rock elastic modulus on the slope $\mathrm{CBH}$ is discussed. Secondly, the calculation method of the $\mathrm{CBH}$ of the consequent slabbed rock slope under its self-weight and top loading is proposed according to the superposition principle. Finally, on the basis of the hypothesis that the rock mechanical behavior obeys the statistical damage model, the effect of the rock mechanical parameters $n$ and $\varepsilon_{0}$ on the slope $\mathrm{CBH}$ is studied. The results show that the rock strength has much effect on the slope $\mathrm{CBH}$. If the rock is supposed to be a linear elastic body without failure in Euler's Method, the result from it is the maximum of the slope $\mathrm{CBH}$.
\end{abstract}

\section{Introduction}

Rock masses are often intersected by a single set of steeply dipping discontinuities, such as regular bedding planes or joints, forming a slab or slabbed structure. Meanwhile, the loads on the top of the slope are often encountered in the practical engineering, such as the vehicle load in the transportation engineering and the building load in the civil engineering. When the slope surface is parallel to the discontinuities, under the action of driving force due to the self-weight of rock slabs and top loading, failure by buckling may be initiated, namely, the slabs near the toe of slope buckle gradually and correspondingly the slabs above the buckle slide along a weak interlayer (Figure 1). In the condition of the length and width of the rock slab being far larger than its thickness, the buckling of rock slabs may be simplified as a beam stability problem.

Because buckling of rock slabs is a common phenomenon of slope movements in sedimentary rocks, lots of studies have been conducted to understand the slip-buckling slope failure mechanism. Harrison and Falcon [1] called some naturally formed buckles, roof and wall structures, and cascades. Johnson [2] discussed buckling phenomena related to formation of sheet structures in New England quarry floors. Nemčok et al. [3] and Radbruch-Hall [4] attributed some buckles to "creeps." Kutter [5] briefly discussed buckling in British open pit coal mines. Cavers [6] analyzed mechanisms of singleslab buckling for Euler buckles and three hinged buckles for planar or curved slabs. Also on the basis of Euler's theory, Sun [7] obtained the buckling critical height of the rock slab with an energy equilibrium principle. Hu and Cruden [8] regarded the notion that the modes of buckling were determined by bedding thickness, and accordingly they proposed three buckling modes: Euler buckles, block-flexure buckles, and block buckles. Pant and Adhikary [9] and Adhikary et al. [10] conducted an explicit and implicit finite element numerical study on the mechanism of flexural buckling failure of foliated rock slopes. Qin et al. [11] proposed a catastrophe cusp model to study the failure mechanisms of the slip-buckling slope. Pereira and Lana [12] analyzed a buckling failure occurring in an open pit mine with the numerical method. Supposing that the rock element strength obeys Weibull distribution 
model, Zhang et al. [13] introduced the rock strength into the calculation of the critical buckling height $(\mathrm{CBH})$ of the consequent slabbed rock slope. Qi et al. [14] presented an analytical solution on slip buckling slope failure which fully considers both the effect of earthquake and pore water pressure based on energy equilibrium theory.

However, it can be found from the existing research that although many researchers have conducted rather profound work on the buckling failure of the consequent slabbed rock slope, the following aspects are still to be studied further. First of all, the load acting on the slope is not perfectly considered in the existing studies. Although the loads such as self-weight of rock slabs, groundwater pressure, and the seismic force are considered in the models proposed by many researchers [11, 14], the slope is often subjected to the top loading such as the transportation and building loads which are not considered in the calculation of the $\mathrm{CBH}$ of the consequent slabbed rock slope. Moreover, the rock is assumed to be elastic in the existing studies and cannot fail in strength which is not always true in the practical engineering. Although Zhang et al. [13] introduced the rock strength into the calculation of the $\mathrm{CBH}$ of the consequent slabbed rock slope, they did not take into account the top loading of the slope and the cohesion between the neighboring rock slabs, and the buckling deformation deflection curve equation of the rock slab they adopted is also unreasonable.

Therefore, the present paper is aimed at presenting a comprehensive theoretical model for the flexural buckling of the consequent slabbed rock slope under top loading. Firstly, suppose the rock to be a perfect elastic material; the calculation method of the $\mathrm{CBH}$ of the vertical slabbed rock slope is proposed, and then it is generalized to that of the consequent slabbed rock slope. Secondly, assume the rock strength obeys Weibull distribution, and then the effect of its strength property on the $\mathrm{CBH}$ of the vertical slabbed rock slope is discussed. In all, the proposed method provides a way to consider the effect of rock strength and top loading on the $\mathrm{CBH}$ of the consequent slabbed rock slope.

\section{Flexural Buckling Model for the Consequent Slabbed Rock Slope under Its Self-Weight Assuming the Rock to Be a Perfect Elastic Material}

2.1. Flexural Buckling Model for the Vertical Slabbed Rock Slope under Its Self-Weight. Because the vertical one is a special case of the consequent slabbed rock slope, the vertical slabbed rock slope is firstly studied, and then its result can be generalized to the consequent slabbed rock slope. Zhang and $\mathrm{Li}$ [15] summarized the failure mode of the vertical slabbed rock slope into the following two, namely, buckling failure and toppling failure, shown in Figures 2(a) and 2(b), and the former is only discussed here. The classical buckling theory (Euler's Method) makes the following assumptions in the derivation of the formulae [16]: (1) The column is elastic and obeys Hooke's Law. (2) The slope of the deflection curve can be approximated by a linear function. (3) The column is weightless. (4) The column is perfectly straight.

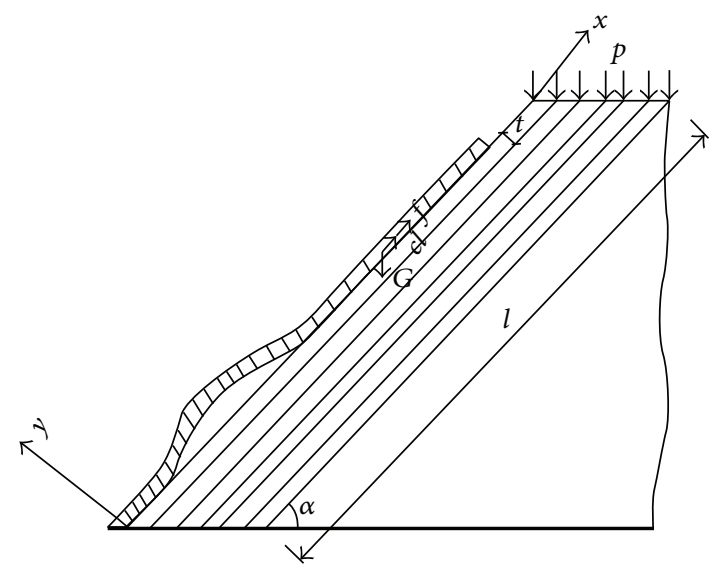

FIGURE 1: Buckling failure model for the consequent slabbed rock slope.

According to the assumptions above, the critical buckling load is

$$
P_{\mathrm{cr}}=\frac{\pi^{2} E I}{(\mu l)^{2}}
$$

where $P_{\mathrm{cr}}$ is the critical buckling load, $\mathrm{N} ; E$ is Young's modulus of the material, $\mathrm{Pa}$; $I$ is the moment of inertia, $\mathrm{m}^{4} ; l$ is the length of the column, $\mathrm{m}$; and $\mu$ is a constant describing end conditions, for pinned ends, $\mu=1$.

The buckling instability of the vertical slabbed rock slope is triggered by the gravity of the rock slope and the cohesion and frictional force between the neighboring rock slabs, and the loads above are linear ones along the height of the rock slab. Therefore, it cannot be solved with the classic buckling theory (Euler's Method), which will otherwise lead to the engineering accident or unnecessary engineering cost.

The instability model for the vertical slabbed rock slope under its self-weight should satisfy the following hypothesis: (1) only the self-weight of the rock slab and the cohesion between the neighboring rock slabs are included here, and the top loading of the rock slab is not considered; (2) the bottom of the rock slope is embedded into the ground, so it can be regarded as the fixed constraint. The buckling failure mode of the vertical slabbed rock slope is shown as Figure 2(a). It can be seen that the upper rock slab of the slope slips down along the bedding plane at the initial stage of the slope instability and its normal deformation on the bedding plane is restricted because of the neighboring rock slab. Therefore, the buckling instability failure mode of the vertical slabbed rock slope can be simplified as the mechanical model with the top sliding and bottom fixation constraints, shown in Figure 2(c), with the corresponding coordinate system. Assume the depth of the rock slab perpendicular to the plane is the unit; the critical buckling load of the slope can be solved with the energy method. It can be seen from Figure 2(c) that the axial part of the rock slab will deviate from the original position, namely, 


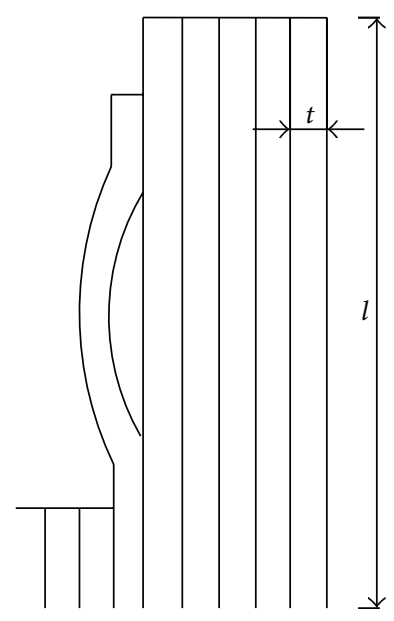

(a)

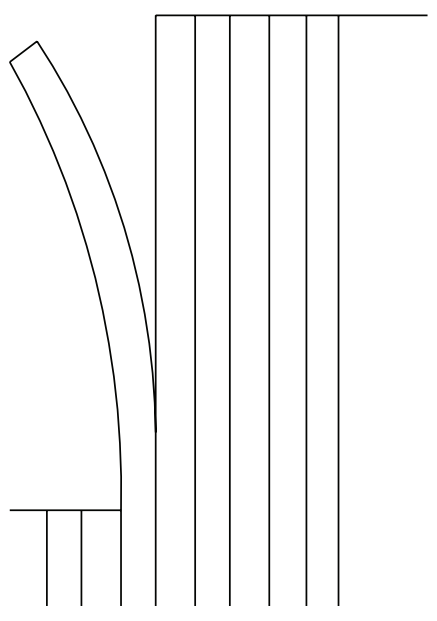

(b)

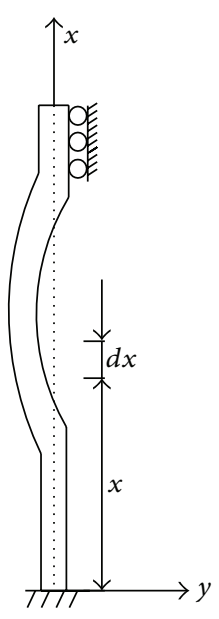

(c)

FIGURE 2: Failure modes of the vertical slabbed rock slope and the pressure bar model. (a) Buckling failure; (b) toppling failure; (c) the calculation model of the pressure bar.

$x$ direction. Assume $v$ is the deflection of the rock slab; its geometrical and mechanical boundary conditions are

$$
\begin{gathered}
\left.v\right|_{x=0}=0, \\
\left.v\right|_{x=l}=0, \\
\left.v^{\prime}\right|_{x=0}=0 .
\end{gathered}
$$

According to the experiments of rock slab under uniaxial compression by Sun [7], it is reasonable to assume the deflection curve is

$$
v=\delta\left(1-\cos \frac{2 \pi x}{l}\right),
$$

where $\delta$ is the constant to determine. It is easily verified that (3) satisfies the boundary condition.

According to elastic theory [17], the strain energy $U$ stored in the rock slab is

$$
U=\int_{0}^{l} \frac{E I}{2}\left(v^{\prime \prime}\right)^{2} d x=\frac{4 E I \pi^{4} \delta^{2}}{l^{3}} .
$$

As shown in Figure 2(c), assume the differential length along the deflection curve is $d s$ when $x$ increases from $x$ to $x+d x$; the distance $d \lambda(x)$ that the load above $x$-section moves is

$$
d \lambda(x)=d s-d x=\left(\sqrt{1+\left(v^{\prime}\right)^{2}}-1\right) d x .
$$

Making Taylor extension for (5) and ignoring the highorder items, (5) is abbreviated:

$$
d \lambda(x)=\frac{1}{2}\left(v^{\prime}\right)^{2} d x .
$$

Therefore, the displacement $\lambda(x)$ that the rock slab moves along $x$-axis is as follows:

$$
\lambda(x)=\int_{0}^{x} \frac{1}{2}\left(v^{\prime}\right)^{2} d x=\frac{\pi^{2} \delta^{2}}{l^{2}}\left(x-\frac{l}{4 \pi} \sin \frac{4 \pi x}{l}\right) .
$$

The corresponding potential energy $W$ of the rock slab is

$$
W=\int_{0}^{l}(q-c) \lambda(x) d x=\frac{\pi^{2} \delta^{2}}{2}(q-c),
$$

where $q=\gamma t$ is the gravitational load intensity, $\mathrm{N} / \mathrm{m}^{2} ; \gamma$ is the unit weight of the rock slab, $\mathrm{N} / \mathrm{m}^{3} ; t$ is the slab thickness (joint spacing), $\mathrm{m}$; and $c$ is the cohesion between the neighboring rock slabs, $\mathrm{Pa}$.

The overall potential energy of the bending rock slab is $\Pi=U-W$, and then according to the principle of minimum potential energy $\partial \Pi / \partial \delta=0$, we obtain

$$
P_{\mathrm{cr}}=(q-c) l_{\mathrm{cr} 0}=\frac{8 \pi^{2} E I}{l_{\mathrm{cr} 0}^{2}},
$$

where $P_{\mathrm{cr}}$ is the critical force, $\mathrm{N} / \mathrm{m}$, and $l_{\mathrm{cr} 0}$ is the $\mathrm{CBH}$ of the vertical slabbed rock slope under its self-weight. $I=(1 / 12) t^{3}$ is the moment of inertia, $\mathrm{m}^{4}$.

In order to compare with the result obtained with Euler's Method, (9) can be changed into

$$
(q-c) l_{\mathrm{cr} 0}=\frac{\pi^{2} E I}{\left(0.35 l_{\mathrm{cr} 0}\right)^{2}} .
$$

Therefore, the $\mathrm{CBH} l_{\mathrm{cr} 0}$ of the vertical slabbed rock slope under its self-weight is

$$
l_{\mathrm{cr} 0}=\sqrt[3]{\frac{\pi^{2} E I}{0.12(q-c)}}=\sqrt[3]{\frac{\pi^{2} E t^{3}}{1.44(\gamma t-c)}},
$$

where the meaning of all the parameters is stated as above.

2.2. Flexural Buckling Model for the Consequent Slabbed Rock Slope under Its Self-Weight. However, the completely vertical slabbed rock slope is rare in practical engineering; almost all of the slabbed rock slops are consequent or anticonsequent. 
Therefore, in order to make the study result more applicable, the study on the $\mathrm{CBH}$ of the consequent slabbed rock slope shown in Figure 1 is done next. Because the self-weight, cohesion, and friction force will all exist in the consequent slabbed rock slope, the residual driving force $F_{x}$ of the rock slab along the interlayer is

$$
F_{x}=\gamma l \sin \alpha-\gamma l \cos \alpha \cdot \tan \phi-c l
$$

where $\alpha$ is the slope dip angle (i.e., the slab dip angle), $\phi$ is the friction angle between the neighboring rock slabs, and the other parameters are as stated above.

Therefore, according to the calculation result of the vertical slabbed rock slope, namely, substituting $\gamma t$ into (11) with $\gamma t(\sin \alpha-\cos \alpha \cdot \tan \phi)$, the $\mathrm{CBH} l_{\text {crl }}$ of the consequent slabbed rock slope under its self-weight is

$$
l_{\mathrm{cr} 1}=\sqrt[3]{\frac{\pi^{2} E t^{3}}{1.44[\gamma t(\sin \alpha-\cos \alpha \cdot \tan \phi)-c]}}
$$

It can be seen that the vertical slabbed rock slope is a special case of the consequent one.

2.3. Calculation Examples. The calculation example by Xiao and Yang [18] is discussed here. The rock slope is divided by a set of consequent joints, and the thickness of the rock slab is $0.63 \mathrm{~m}$. The rock slope will be prone to flexural buckling failure under its self-weight. The $\mathrm{CBH} l_{\mathrm{cr}}^{\prime}$ of the slope obtained by Xiao and Yang [18] with Euler's Method is (ignoring the cohesion between the neighboring rock slabs)

$$
l_{\mathrm{cr}}^{\prime}=\sqrt[3]{\frac{\pi^{2} E t^{3}}{6 \gamma(\sin \alpha-\cos \alpha \operatorname{tg} \phi)}} .
$$

It can be seen that the result obtained from (13) is 1.61 times that obtained from (14) when the cohesion between the neighboring rock slabs is not considered. So it can be regarded that the result obtained from (14) is too conservative, which will lead to the unnecessary engineering cost. The reason leading to this result is that Xiao and Yang [18] assumed the gravity of the rock slab to be a concentrated load acting on its top, which will reduce the $\mathrm{CBH}$ of the slope. Meanwhile, the cohesion between the neighboring rock slabs is also neglected in their study.

The effect of the parameters such as the slope dip angle on the $\mathrm{CBH}$ is discussed here. Assume $E, \gamma, t, \alpha, \phi, c$ are $10 \mathrm{GPa}$, $25300 \mathrm{~N} / \mathrm{m}^{3}, 0.63 \mathrm{~m}, 70^{\circ}, 15^{\circ}$, and $5 \mathrm{kPa}$, respectively, and the other parameters remain unchanged when one of them is studied. The variation of the slope $\mathrm{CBH}$ with $\alpha, c, \phi$, and $E$ obtained from (3) is shown as in Figures 3-6. It can be found that the slope $\mathrm{CBH}$ gradually decreases with increasing the slope dip angle, but with the increase in the friction angle and cohesion between the neighboring rock slabs and the rock elastic modulus, the slope $\mathrm{CBH}$ increases.

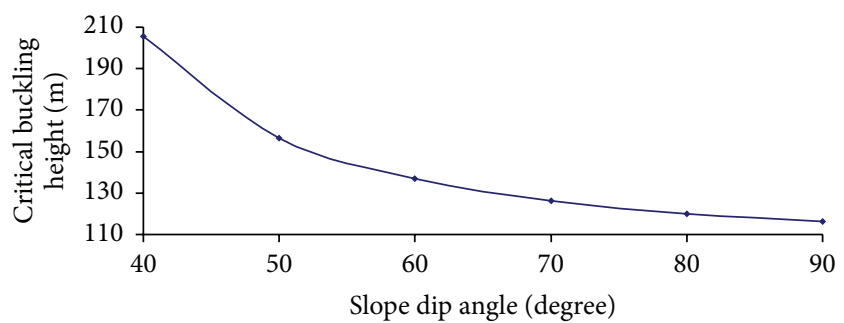

FIgUre 3: Variation of slope $\mathrm{CBH}$ with the slope dip angle.

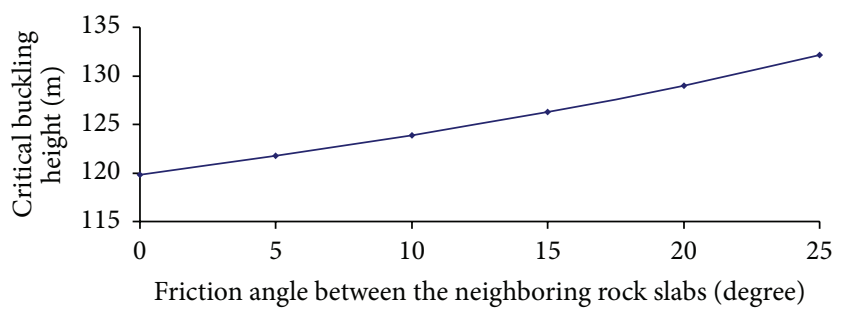

FIGURE 4: Variation of the slope $\mathrm{CBH}$ with the friction angle between the neighboring rock slabs.

\section{Flexural Buckling Model for the Consequent Slabbed Rock Slope under Self-Weight and Top Loading Assuming the Rock to Be a Perfect Elastic Material}

Although the flexural buckling model for the consequent slabbed rock slope under its self-weight is only discussed in Section 2, there are many other loads such as the transportation and building loads on the slope top in many conditions. Therefore, the instability of the consequent slabbed rock slope under the slope top loading and its self-weight should be studied.

When only the top loading shown in Figure 1 is considered, the $\mathrm{CBH}$ of the slope can be solved with Euler's Method, namely, (1). According to boundary condition of the slope, $\mu$ should be equal to 0.7 . Therefore, the $\mathrm{CBH} l_{\mathrm{cr} 2}$ of the slabbed rock slope is

$$
l_{\mathrm{cr} 2}=\sqrt{\frac{\pi^{2} E t^{2}}{5.88 p \sin \alpha}},
$$

where $p$ is the top loading intensity of the slope, $\mathrm{N} / \mathrm{m}^{2}$, and the other parameters are as stated above.

Assume the critical buckling load of the slabbed rock slope under the following three load conditions such as its self-weight and top loading, its self-weight, and top loading is $P_{\mathrm{cr}}, P_{\mathrm{cr} 1}$, and $P_{\mathrm{cr} 2}$. Then, we can obtain

$$
P_{\mathrm{cr}}=P_{\mathrm{cr} 1}+P_{\mathrm{cr} 2} \text {. }
$$

If it is assumed that the critical height of the slabbed rock slope under its self-weight and top loading is $l_{\mathrm{cr}}$, and according to Euler's Method, we can obtain

$$
\frac{\pi^{2} E I}{\left(\mu l_{\mathrm{cr}}\right)^{2}}=\frac{\pi^{2} E I}{\left(\mu l_{\mathrm{cr} 1}\right)^{2}}+\frac{\pi^{2} E I}{\left(\mu l_{\mathrm{cr} 2}\right)^{2}}
$$




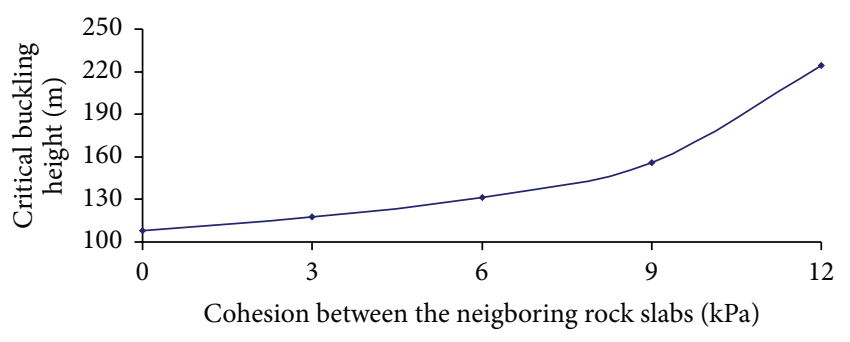

FIGURE 5: Variation of the slope CBH with the cohesion between the neighboring rock slabs.

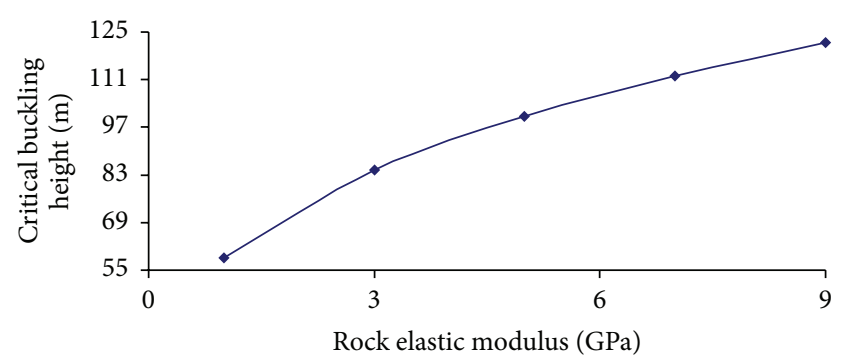

FIGURE 6: Variation of the slope CBH with the rock elastic modulus.

Then, we can obtain

$$
\frac{1}{l_{\mathrm{cr}}^{2}}=\frac{1}{l_{\mathrm{cr} 1}^{2}}+\frac{1}{l_{\mathrm{cr} 2}^{2}}
$$

Also take the calculation example in Section 2.3 as an example; the variation of the slope $\mathrm{CBH}$ with the top loading is studied. The parameters in Section 2.3, namely, $E=10 \mathrm{GPa}$, $\gamma=25300 \mathrm{~N} / \mathrm{m}^{3}, t=0.63 \mathrm{~m}, \alpha=70^{\circ}, \phi=15^{\circ}$, and $c=5 \mathrm{kPa}$, are also adopted; we can obtain

$$
\frac{1}{l_{\mathrm{cr}}^{2}}=\frac{p}{7.1 e 9}+\frac{1}{121.89^{2}}
$$

It can be seen from Figure 7 that the slope $\mathrm{CBH}$ almost linearly decreases with increasing top loading.

\section{Flexural Buckling Model for the Consequent Slabbed Rock Slope regarding the Rock to Be the Damage Material}

4.1. The Statistical Damage Constitutive Model for a Rock. With Euler's Method, the rock is assumed to be a perfect linear elastic body and it does not fail. So only the deformational parameter such as the rock elastic modulus is considered, while its strength one is not. However, the rock is a kind of natural damage geological body and it contains many randomly distributed microcracks, which will have effect on the rock strength. The statistical damage mechanics is a powerful tool to study the occurrence, propagation, and coalescence processes of these microcracks and their effect on rock mechanical behaviors. By means of it, the distribution law of these microcracks in rock such as normal or Weibull distribution is assumed so as to build up the mesoscopic elements with strength in a rock and to determine its damage state.

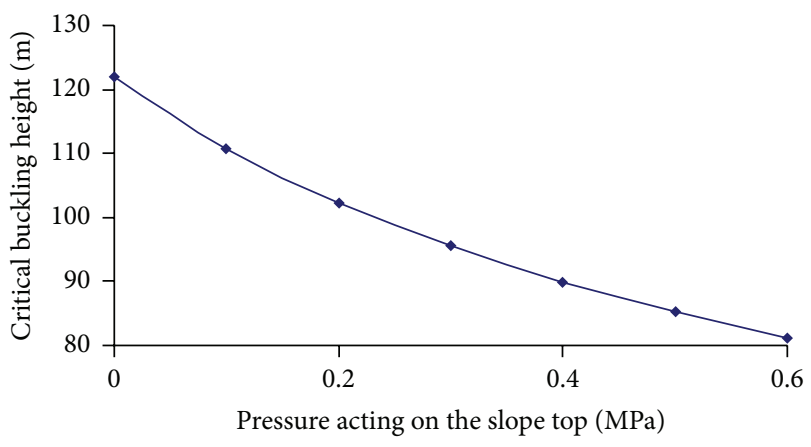

FIGURE 7: Variation of the slope CBH with the load on the top of the slope.

Thus, a damage statistical constitutive model for a rock can be set up. Till now, much progress in the study of damage statistical constitutive models has been made [19-22]. The establishment of a rock damage statistical constitutive model is mainly based on the following two aspects: (1) choose the strength criteria for the rock mesoscopic element, for instance, the maximum principle strain criterion, Mohr-Coulomb criterion, and Drucker-Prager criterion; and (2) determine the distribution law of the rock mesoscopic element strength, for example, power function distribution and Weibull distribution. The studies show that the damage constitutive model based on Weibull distribution is better than that based on power function distribution, and its calculation process is easier. Therefore, the damage constitutive model based on Weibull distribution and the maximum principle strain criterion is adopted here.

The strength of mesoscopic elements obeys the following Weibull distribution function [19]:

$$
P(\varepsilon)= \begin{cases}\frac{n}{\varepsilon_{0}}\left(\frac{\varepsilon}{\varepsilon_{0}}\right)^{n-1} \exp \left[-\left(\frac{\varepsilon}{\varepsilon_{0}}\right)^{n}\right] & \varepsilon>0 \\ 0 & \varepsilon \leq 0,\end{cases}
$$

where $\varepsilon$ is an elemental strength parameter or stress level, and because the strain strength theory is adopted here, it denotes strain; $n$ and $\varepsilon_{0}$ are the distribution parameters, which can be obtained by fitting with the test stress-strain curve of the rock; and $P(\varepsilon)$ is the percentage of damaged ones out of the total number of the mesoscopic elements in the rock.

Therefore, the damage $D$ of the rock can be defined as

$$
D=1-\frac{E}{E_{0}}=1-\exp \left[-\left(\frac{\varepsilon}{\varepsilon_{0}}\right)^{n}\right]
$$

where $D$ takes a value between 0 and 1 corresponding to damage states of the rock from undamaged to fully damaged; $E_{0}$ and $E$ are the elastic moduli of the rock without any damage and with some damage, respectively.

Assume the mechanical behavior of the rock mesoscopic elements obeys Hooke law, its constitutive law is

$$
\sigma=E \varepsilon(1-D),
$$

where $\sigma$ and $\varepsilon$ are the stress and strain for the rock, respectively. 


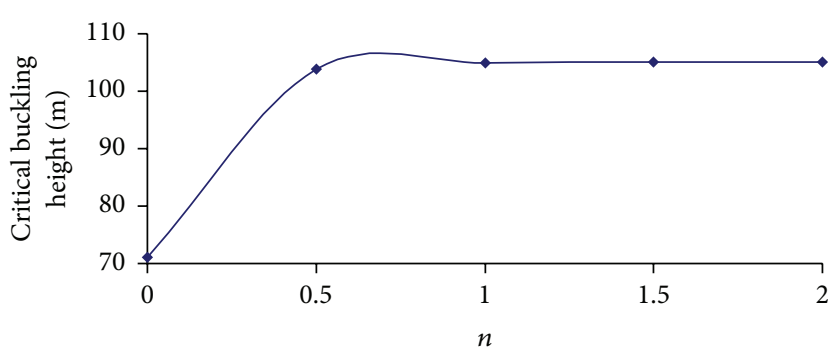

FIGURE 8: Variation of the slope CBH with $n\left(\varepsilon_{0}=0.02\right)$.

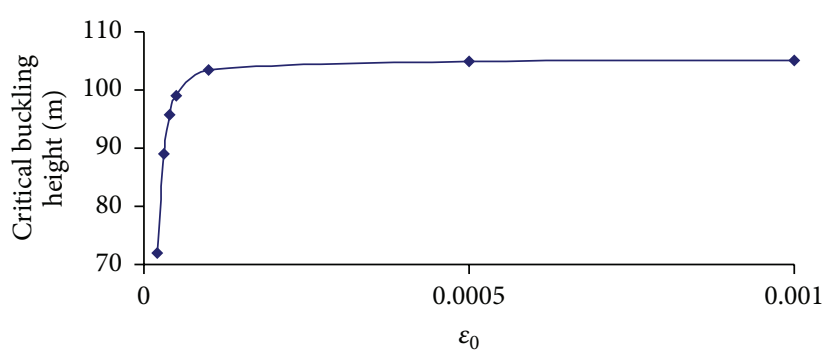

Figure 9: Variation of the slope $\mathrm{CBH}$ with $\varepsilon_{0}(n=2)$.

4.2. Flexural Buckling Model for the Consequent Slabbed Rock Slope under Its Self-Weight and Top Loading Based on the Rock Statistical Damage Constitutive Model. As stated above, the rock is a kind of natural damage geological body in which the damage will increase even under little load. Therefore, it is unsuitable to assume the rock to be the linear elastic body without any damage.
So in order to discuss the effect of the rock damage on the $\mathrm{CBH}$ of the slope, the flexural buckling model for the consequent slabbed rock slope based on Weibull statistical damage constitutive model for the rock is set up. From (21), it can be known that the rock damage and its evolution are mainly reflected by the variation of the rock elastic modulus. Therefore, substituting (21) into (18) leads to

$$
\frac{1}{l_{\mathrm{cr}}^{2}}=\frac{1}{\sqrt[3]{\left(\pi^{2} t^{3} E_{0} \exp \left[-\left(\varepsilon / \varepsilon_{0}\right)^{n}\right] / 1.44[\gamma t(\sin \alpha-\cos \alpha \cdot \tan \phi)-c]\right)^{2}}}+\frac{1}{\pi^{2} E_{0} \exp \left[-\left(\varepsilon / \varepsilon_{0}\right)^{n}\right] t^{2} / 48 p \sin \alpha}
$$

where

$$
\varepsilon=\frac{p \sin \alpha+\gamma t(\sin \alpha-\cos \alpha \cdot \tan \phi)-c}{E} .
$$

Because when the buckling failure of the slope occurs, the rock damage is rather little, so $E$ can be replaced with $E_{0}$; namely,

$$
\varepsilon \approx \frac{p \sin \alpha+\gamma t(\sin \alpha-\cos \alpha \cdot \tan \phi)-c}{E_{0}} .
$$

The effect of $n$ and $\varepsilon_{0}$ on the $\mathrm{CBH}$ of the slope is discussed. The parameters in Section 2.3, namely, $E=10 \mathrm{GPa}, \gamma=$ $25300 \mathrm{~N} / \mathrm{m}^{3}, t=0.63 \mathrm{~m}, \alpha=70^{\circ}, \phi=15^{\circ}$, and $c=5 \mathrm{kPa}$, are also adopted; at the same time, the parameters of $n$ and $\varepsilon_{0}$ are assumed to be 2.0 and 0.02 , respectively, by experience. If we assume the pressure on the top of the slope is $0.2 \mathrm{MPa}$, the $\mathrm{CBH}$ of the slope is $105.03 \mathrm{~m}$ with (23). By comparison, the corresponding result is $102.34 \mathrm{~m}$ when the rock is assumed to be a perfect elastic body. If ignoring the calculation error, they are assumed to be equal. The effects of $n$ and $\varepsilon_{0}$ on the CBH of the slope are discussed. It can be seen from Figure 8 that the $\mathrm{CBH}$ of the slope increases from $71.01 \mathrm{~m}$ to $105.03 \mathrm{~m}$ when $n$ increases from 0 to 2 , which indicates that $n$ has much effect on the calculation result. However, from the increase extent, the $\mathrm{CBH}$ of the slope increases much more when $n$ increases from 0 to 0.5 , and then it increases rather less. It shows that the effect of $n$ on the calculation result is little when it increases to a certain value, and the similar result can also be found in Figure 9.

In order to illustrate the effect of $n$ and $\varepsilon_{0}$ on the rock stress-strain curve, the results are given in Figures 10 and 11. It can be seen that the rock elastic modulus and climax strength will both vary with them, and in some cases the variation of the rock strength is more obvious. Therefore, it can be regarded that the effect of the rock strength on the $\mathrm{CBH}$ of the slope is much. When the rock is assumed to be a perfect elastic body, namely, its climax strength is infinite, the $\mathrm{CBH}$ of the slope will reach its maximum, which can be seen from Figures 8 and 9 . So the rock strength and deformational behavior 


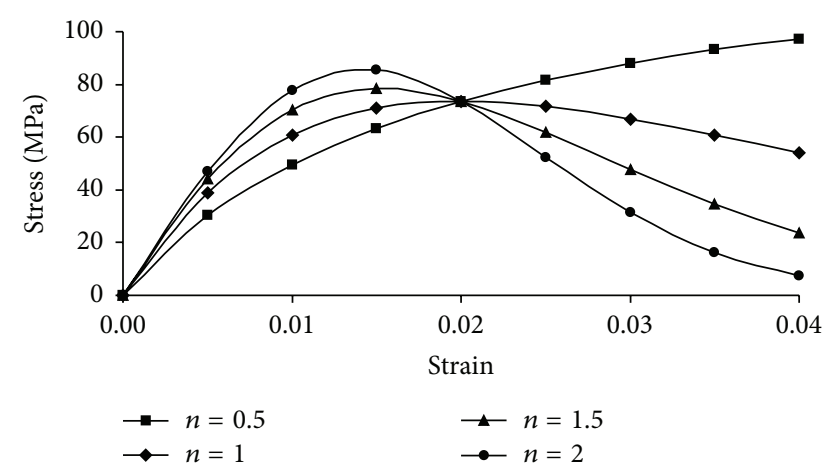

FIGURE 10: Variation of the rock stress-strain with $n$ at $\varepsilon_{0}=0.02$.

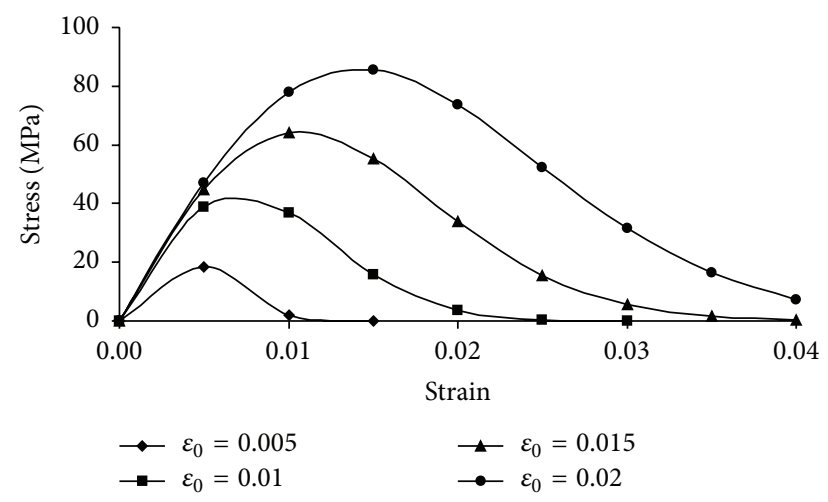

FIGURE 11: Variation of the rock stress-strain with $\varepsilon_{0}$ at $n=2$.

should be considered at the same time in order to accurately obtain the $\mathrm{CBH}$ of the slope.

\section{Conclusions}

Assuming the rock to be a perfect elastic material, we firstly investigate the calculation method of the $\mathrm{CBH}$ of the vertical slabbed rock slope under its self-weight based on the energy principle and then extend it to that of the consequent slabbed rock slope. The effect of slope dip angle, friction angle, and cohesion between the neighboring rock slabs and rock elastic modulus on the slope CBH is discussed. It can be seen that the slope $\mathrm{CBH}$ gradually decreases with increasing the slope dip angle, but it will increase with the increase in the friction angle and cohesion between the neighboring rock slabs and the rock elastic modulus.

According to the superposition principle of Euler's Method, we deduce the calculation method of the $\mathrm{CBH}$ of the consequent slabbed rock slope under its self-weight and top loading. Meanwhile, the effect of top loading on the $\mathrm{CBH}$ of the consequent slabbed rock slope is also discussed. It can be seen that the slope $\mathrm{CBH}$ almost linearly decreases with increasing top loading.

Thirdly, assuming the rock mechanical behavior obeys the statistical damage model, we establish the corresponding calculation method of the $\mathrm{CBH}$ of the consequent slabbed rock slope under its self-weight and top loading. We also discuss the effect of the rock strength characteristic parameters $n$ and $\varepsilon_{0}$ on the slope $\mathrm{CBH}$, and the results show that their effect on the slope $\mathrm{CBH}$ is large when $n$ and $\varepsilon_{0}$ are little, and then when they increase to a certain value, their effect will become very little. Overall, the proposed method provides a way to calculate the $\mathrm{CBH}$ of the consequent slabbed rock slope under its self-weight and top loading.

Finally, it is noted that the proposed method is more suitable to the case that the top loading cannot be ignored comparing with the self-weight of the rock slope; for example, there are heavy building and transportation load on the top of the rock slope.

\section{Competing Interests}

The authors declare that they have no competing interests.

\section{Acknowledgments}

This study is supported by "the Fundamental Research Funds for the Central Universities (2652014019/2652015263) of China" and "China Scholarship Funds (2016)."

\section{References}

[1] J. V. Harrison and N. L. Falcon, "Gravity collapse structures and mountain ranges, as exemplified in south-western Iran," Quarterly Journal of the Geological Society of London, vol. 92, no. 1-4, pp. 91-102, 1936.

[2] A. M. Johnson, Physical Processes in Geology, Freeman, Cooper \& Co, San Francisco, Calif, USA, 1970.

[3] A. Nemčok, J. Pašek, and J. Rybář, "Classification of landslides and other mass movements," Rock mechanics, vol. 4, no. 2, pp. 71-78, 1972.

[4] D. H. Radbruch-Hall, "Gravitational creep of rock masses on slopes," in Rockslides and Avalanches, 1, Natural Phenomena, B. Voight, Ed., pp. 607-657, Elsevier, New York, NY, USA, 1978.

[5] H. K. Kutter, "Mechanisms of slope failure other than pure sliding," in Rock Mechanics, International Center for Mechanical Sciences, Courses and Lectures, L. Muller, Ed., vol. 165, Springer, New York, NY, USA, 1974.

[6] D. S. Cavers, "Simple methods to analyze buckling of rock slopes," Rock Mechanics and Rock Engineering, vol. 14, no. 2, pp. 87-104, 1981.

[7] G. Z. Sun, Rock Mass Structure Mechanics, Science Press, Beijing, China, 1988, 1988 (Chinese).

[8] X.-Q. Hu and D. M. Cruden, "Buckling deformation in the Highwood Pass, Alberta, Canada," Canadian Geotechnical Journal, vol. 30, no. 2, pp. 276-286, 1993.

[9] S. R. Pant and D. P. Adhikary, "Technical note: implicit and explicit modelling of flexural buckling of foliated rock slopes," Rock Mechanics and Rock Engineering, vol. 32, no. 2, pp. 157-164, 1999.

[10] D. P. Adhikary, H.-B. Mühlhaus, and A. V. Dyskin, "A numerical study of flexural buckling of foliated rock slopes," International Journal for Numerical and Analytical Methods in Geomechanics, vol. 25, no. 9, pp. 871-884, 2001.

[11] S. Q. Qin, J. J. Jiao, and S. J. Wang, "A cusp catastrophe model of instability of slip-buckling slope," Rock Mechanics and Rock Engineering, vol. 34, no. 2, pp. 119-134, 2001. 
[12] L. C. Pereira and M. S. Lana, "Stress-strain analysis of buckling failure in phyllite slopes," Geotechnical and Geological Engineering, vol. 31, no. 1, pp. 297-314, 2013.

[13] L. M. Zhang, S. R. Lv, J. H. Zhang, and H. Y. Liu, "Instability analysis of bedding rock slope based on the statistical constitutive damage model," Geotechnical Investigation \& Survey, no. 9, pp. 7-29, 2014 (Chinese).

[14] S. W. Qi, H. X. Lan, and J. Y. Dong, "An analytical solution to slip buckling slope failure triggered by earthquake," Engineering Geology, vol. 194, pp. 4-11, 2015.

[15] T. J. Zhang and Y. P. Li, "Linear viscoelasticity stability analysis of bluff rock slope," Mechanics in Engineering, vol. 25, no. 6, pp. 51-54, 2003 (Chinese).

[16] A. Chajes, Principles of Structural Stability Theory, Civil Engineering and Engineering Mechanics Series, Prentice Hall, Englewood Cliffs, NJ, USA, 1974.

[17] D. O. Brush and B. P. Almroth, Buckling of Bars, Plates and Shells, McGraw-Hill, New York, NY, USA, 1975.

[18] S. F. Xiao and S. B. Yang, Rock Mass Mechanics, Geological Press, Beijing, China, 1987 (Chinese).

[19] W. Weibull, "A statistical distribution function of wide applicability," Journal of Applied Mechanics, vol. 18, pp. 293-297, 1951.

[20] D. Krajcinovic and M. A. G. Silva, "Statistical aspects of the continuous damage theory," International Journal of Solids and Structures, vol. 18, no. 7, pp. 551-562, 1982.

[21] Z.-L. Wang, Y.-C. Li, and J. G. Wang, "A damage-softening statistical constitutive model considering rock residual strength," Computers \& Geosciences, vol. 33, no. 1, pp. 1-9, 2007.

[22] H. Y. Liu and X. P. Yuan, "A damage constitutive model for rock mass with persistent joints considering joint shear strength," Canadian Geotechnical Journal, vol. 52, no. 8, pp. 1136-1143, 2015. 


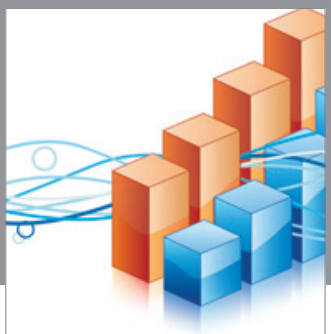

Advances in

Operations Research

vatem alat4

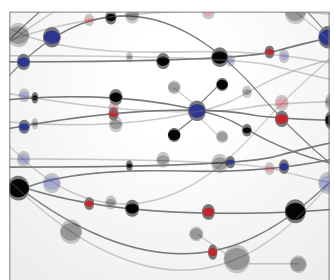

\section{The Scientific} World Journal
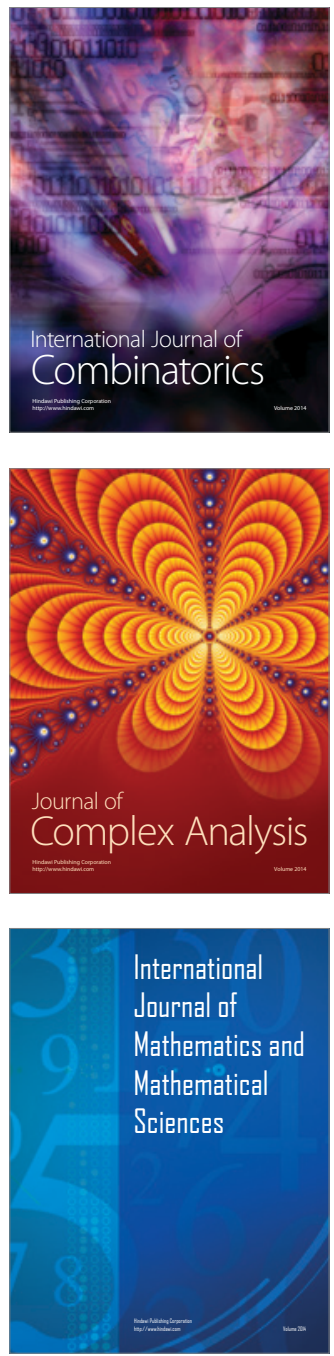
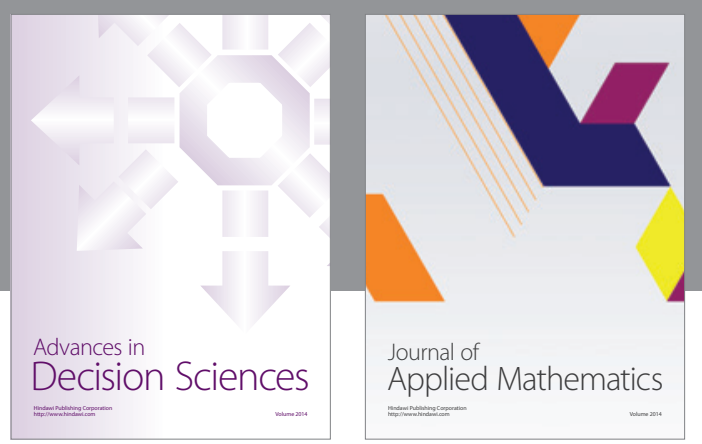

Algebra

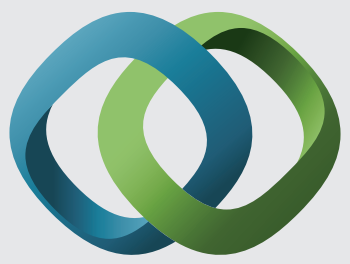

\section{Hindawi}

Submit your manuscripts at

http://www.hindawi.com
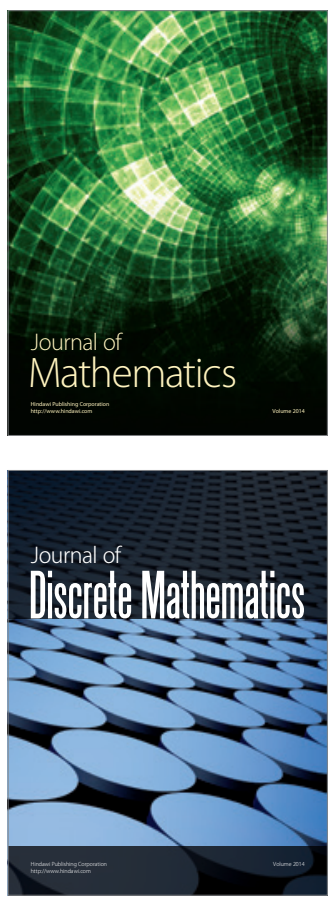

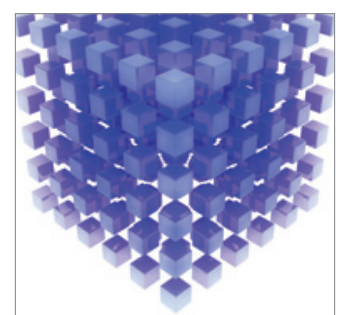

Mathematical Problems in Engineering
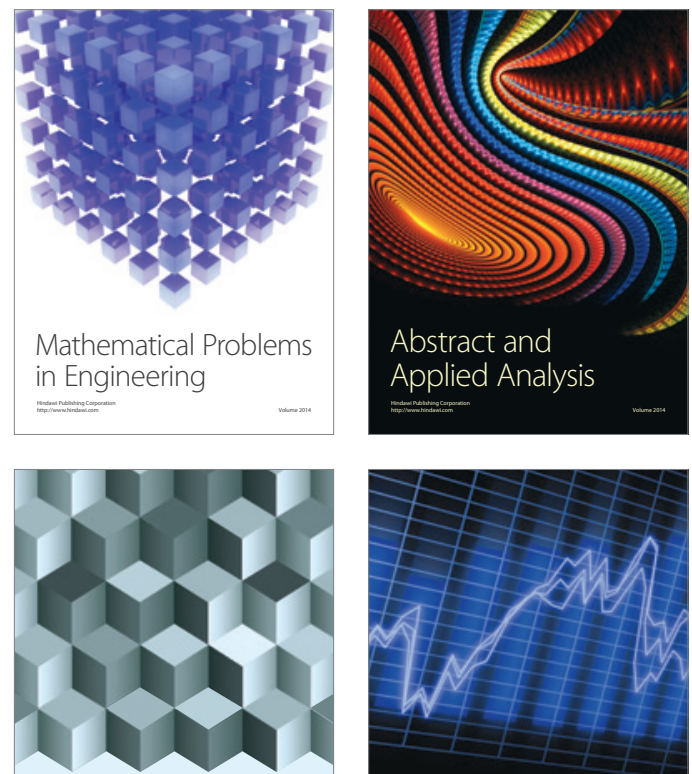

Journal of

Function Spaces

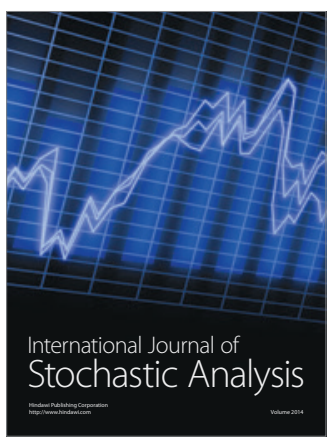

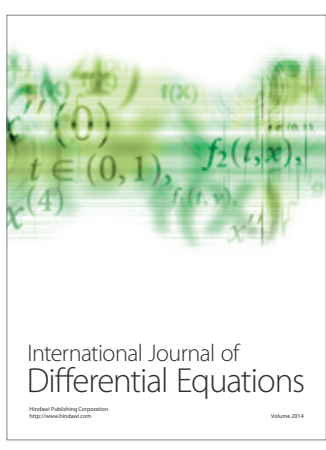
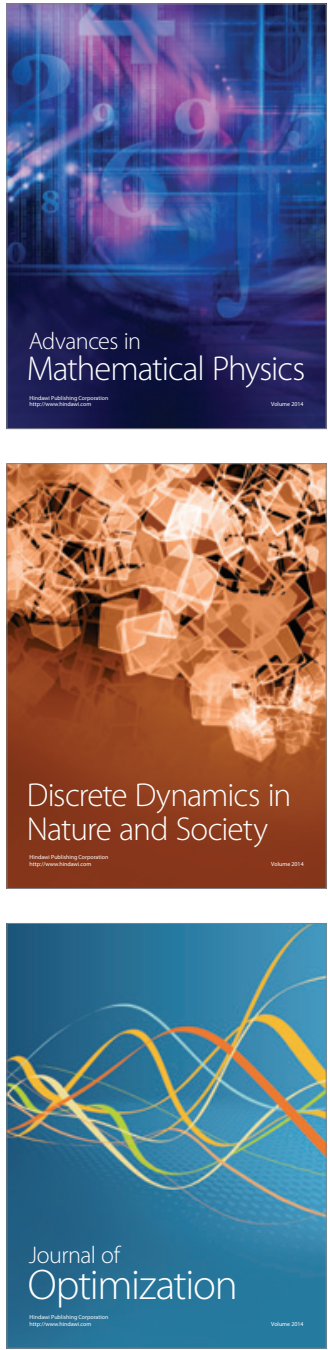